\title{
In Vitro Release of Metoclopramide from Hydrophobic Matrix Tablets. Influence of Hydrodynamic Conditions on Kinetic Release Parameters
}

\author{
Paloma Frutos, ${ }^{*}, a$ Cristina PABÓN, ${ }^{a}$ José L. LAStres, ${ }^{a}$ and Gloria Frutos ${ }^{b}$ \\ Department of Pharmaceutical Technology, ${ }^{a}$ Department of Statistics and Operational Research, ${ }^{b}$ Complutense University, \\ Madrid, Spain. Received April 6, 2001; accepted July 9, 2001
}

\begin{abstract}
There has been growing interest in the subject of drug delivery and the design and evaluation of controlledrelease systems. The simplest way to control the release of an active agent is to disperse it in an inert polymeric matrix. Controlled-release systems are of interest because they are technologically simple, relatively cheap, and practically unaffected by physiological changes. In this study, a new matrix system was formed by an active principle, metoclopramide hydrochloride, scattered into a biocompatible hydrophobic polymerical mesh, polyamide 12, to achieve sustained and controlled delivery of metoclopramide hydrochloride. This research was conducted to investigate the in vitro drug release behavior from these new inert polymeric matrix tablets. The drug release process was investigated both experimentally and by means of mathematical models. Different models were applied for the evaluation of drug release data. On the basis of our results, a biexponential equation was proposed, $Q=Q_{\text {fast }}^{1}\left(1-e^{-K_{\text {fast }} t}\right)+Q_{\text {slow }}^{2}\left(1-e^{-K_{\text {slow }} t}\right)$, in an attempt to explain the mechanism responsible for the release process. Additionally, the influence of the experimental conditions of the dissolution devices, such as rate of flow and $\mathrm{pH}$ of dissolution medium, on the parameters that characterize the release mechanism was studied, and it was found that the main factor was the hydrodynamic condition of rate of flow.
\end{abstract}

Key words metoclopramide; controlled-release; inert matrix tablet; polyamide 12; dissolution profile; mathematical model

Sustained or controlled-release delivery systems can achieve predictable and reproducible release rates, extended duration of activity for short half-life drugs, decreased toxicity, reduction of required dose, optimized therapy, and better patient compliance. ${ }^{1,2)}$ With the aim of maximizing the bioavailability of conventional drugs with minimum side effects, new drug delivery systems continue to attract much attention. ${ }^{3)}$

Matrix-type controlled-delivery systems are popular because of their ease of manufacture. The simple preparation technique involves the compression of a blend of drug and polymer powder by conventional pharmaceutical methods to form disks or tablets. In inert matrix systems, which are also referred to as "monolithic" systems, the active agent is dissolved or dispersed in an inert diffusion barrier. The drug is mixed with an inert polymer that does not interact with biological fluids. Inert matrices should be insoluble and remain intact during the experiment. Drug release is controlled by the polymer properties and structure. ${ }^{4-7)}$ The materials used in the preparation of inert matrices are predominantly hydrophobic polymers. Several studies have dealt with the application of polymers such us polyvinylchloride, polyethylene, ethyl cellulose, acrylic resins, and polyamides. ${ }^{8-11)}$ Study of the toxicological, physicochemical, and pharmacotechnical properties of polyamide 12 have indicated that it is a nontoxic inert polymer with good characteristics for the production of tablets by the direct compression method. In previous reports we have confirmed slow drug release of compressed tablets with polyamide 12 in the composition. $^{12-15)}$

The present study reports the use of polyamide 12 (Orgasol) as a new pharmaceutical vehicle in the design of solid controlled-release dosage forms. Inert polyamide 12 (empirical formula $-\mathrm{NH}-\left[\mathrm{CH}_{2}\right]_{11}-\mathrm{CO}-$ ) is obtained by polycondensation of aminolauric acid. Due to the hydrophobic and inert nature of Orgasol and its good fluidity and cohesion, ${ }^{16)}$ this polymer is a priori suitable for elaborate inert matrix sys- tems. Metoclopramide hydrochloride was chosen as a model drug with high aqueous solubility, because of its pharmacokinetic properties of variable bioavailability (50\%), short plasma half-life, and therapeutic interest. It is recommended for use as a potent antiemetic agent in various types of vomiting $^{17)}$ (e.g., it is the antiemetic of choice for chemotherapyinduced emesis). Metoclopramide is a procainamide derivate with effects based on at least two mechanisms: first it acts in the central nervous system as an antagonist at D2 dopamine receptors; and second, metoclopramide has an agonistic effect on the cholinergic systems in the stomach and gut. ${ }^{18)}$ The result is improved gastroduodenal coordination. High doses of metoclopramide inhibit the effects of serotonergic $\left(5-\mathrm{HT}_{3}\right)$ receptors on neurons in the gut, in addition to the effect of dopaminergic $\mathrm{D}_{2}$ receptors at lower doses. Because the activity of metoclopramide is dose dependent, it is important to control the quantity of drug released from the dosage form.

The aim of this study was to develop a new inert matrix tablet to achieve sustained and controlled delivery of metoclopramide hydrochloride from a hydrophobic polymeric matrix formed by Orgasol. The drug release process was investigated both experimentally and by means of mathematical models. ${ }^{19)}$ Different models were applied for the evaluation of drug release data, and the influence of the experimental conditions of the dissolution devices, such as rate of flow and $\mathrm{pH}$ of the dissolution medium, on the parameters that characterize the release mechanism was studied.

\section{Experimental}

The components of matrix tablets were polyamide 12 (Orgasol 2002 ES 5 NAT, Atochem S.A.) as vehicle, and metoclopramide hydrochloride (Medichem S.A.) as a model drug. All materials were stored at controlled temperature conditions of $20 \pm 1^{\circ} \mathrm{C}$, and relative humidity of $40 \pm 5 \%$.

Tablet Preparation Cylindrical tablets with $14 \mathrm{~mm}$ in diameter and $4.5 \mathrm{~mm}$ thick were prepared by mixing Orgasol $56.4 \mathrm{~g}$ and metoclopramide $36 \mathrm{~g}$ in a Prat rotatory type B mixer, with subsequent compaction by the direct compression method in a rotary tablet machine. The average weight $(500 \mathrm{mg})$ and hardness $(6 \mathrm{~kg})$ of the tablets were based on previously defined parameters and maintained constant for the overall batch. The theoretical 


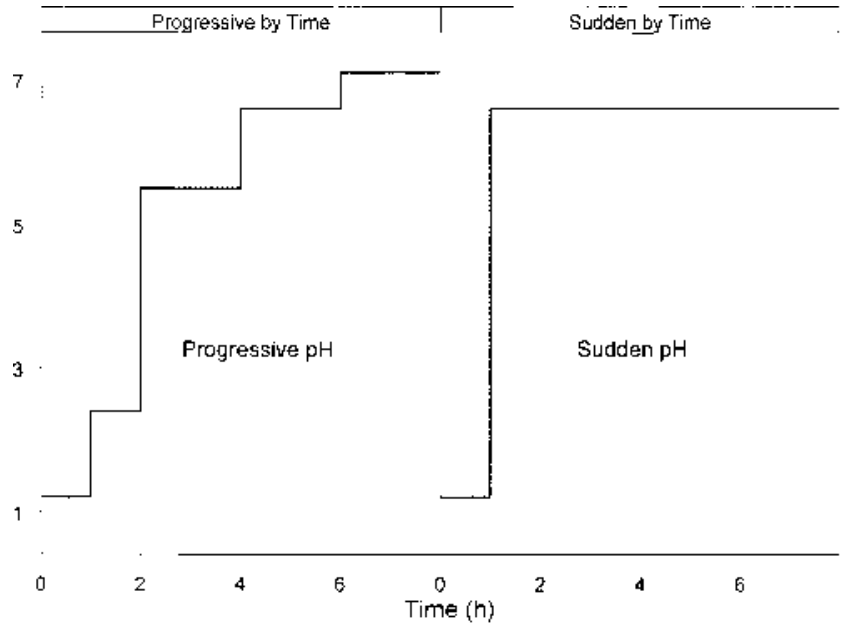

Fig. 1. pH Profiles of Dissolution Medium as a Function of Time as Described in Materials and Methods

dose of active substance was $30 \mathrm{mg}$ per tablet. The size of the batch prepared was 1100 tablets.

Determination of the Pharmacotechnical Parameters of Tablets The following pharmacotechnical assays were performed. Uniformity of weight and drug content was based on the guidelines in the United States Pharmacopeia (USP) XXIII Edition. ${ }^{20}$ The uniformity of weight was confirmed by weighing 10 tablets chosen at random from the laboratory batch. The average weight and hardness ( \pm standard deviation) of the tablets were $500 \pm$ $25 \mathrm{mg}$ and $6 \pm 0.5 \mathrm{~kg}$, respectively. Tablet content was analized by pulverizing 10 individual tablets chosen at random, then $200 \mathrm{mg}$ of each crushed powder was dissolved in $50 \mathrm{ml}$ of distilled water, and the solution was filtered and analyzed spectrophotometrically at $308 \mathrm{~nm}$ after dilution to $1: 10$ The dose of active substance was $30 \pm 0.38 \mathrm{mg}$ per tablet.

Fracture Strength: Ten tablets from the laboratory batch were tested on an Erweka TBI/S apparatus (Heusenstamm, Germany).

Friability: Weight loss was determined in 20 tablets after centrifugation for $4 \mathrm{~min}$ at $25 \mathrm{rpm}$ in an Erweka TAP apparatus (Heusenstamm, Germany).

Disintegration: Six tablets were analyzed in a Pharmatest disintegration apparatus following the guidelines in the USP XXIII Edition. ${ }^{20)}$

Dissolution Test: According to the guidelines for dissolution testing of solid oral products for formulation characterization, the dissolution test should be performed under various test conditions until actual dissolution exceeds $80 \%$ of the labeled amount. ${ }^{21)}$ The in vitro dissolution testing was performed in a flow-through apparatus (Dissotest CE-1, Sotax, Switzerland) adapted to the specifications of apparatus 4 described in the "Europe Pharmacopeia." ${ }^{22)}$ With the flow-through cell apparatus the specimen is placed in a small column that is continuously flushed with a stream of fluid, simultaneously providing the medium and the mechanical agitation for the dissolution of the drug substance. A cell for tablets $22.6 \mathrm{~mm}$ diameter was used. Dissolution tests were carried out at $37^{\circ} \mathrm{C}$, and the samples obtained every 5 min during an $8 \mathrm{~h}$ period, were filtered and their concentrations determined by ultraviolet spectrophotometry at $308 \mathrm{~nm}$. Flow rates of 4,8 , and $16 \mathrm{ml} / \mathrm{min}$ were used. With regard to the $\mathrm{pH}$ of the dissolution medium, two experimental conditions were considered (see Fig. 1): sudden change and progressive gradient. Different $\mathrm{pH}$ values were obtained by means of buffer solutions prepared by mixing different quantities of simulated gastric and intestinal fluids without enzymes, yielding $\mathrm{pH}$ values of 1.2, 2.4, 5.5, 6.6, and 7.1. Each dissolution test was repeated three times.

Determination of Tablet Porosity: The porosities of the tablets were calculated from the tablet dimensions, tablet weights, and true densities of the components, which were determined with a (He)-pycnometer Micromeritics pore-sizer Model 9305.

Mathematical Treatment of Dissolution Data The characterization and comparison of dissolution profiles are recommended in the release Food and Drug Administration (FDA) Guidances. ${ }^{23)}$ Various mathematical techniques may be employed to treat dissolution data. ${ }^{24)}$ In this study the determination of dissolution profiles was carried out using model-dependent or model-independent methods. In the model-dependent approach, the drug release process was investigated using a mathematical model. To determine the release mechanism of metoclopramide from polyamide 12 matrix tablets, drug release profiles were analyzed by fitting dissolution data to kinetic models such as zero order, $Q=K \cdot t$; fickian diffusion based on the model of Peppas, ${ }^{25)} Q / Q_{0}=k t^{n}$; Hixson-Crowell, $Q=Q_{0}-\left[\left(Q_{0}\right)^{1 / 3}-K \cdot t\right]^{3}$; Higuchi square root time model, $Q=K \cdot \sqrt{t}$; first-order model $Q=Q_{0}\left(1-e^{-K t}\right)$; biexponential, $Q=Q_{\text {fast }}^{1}\left(1-e^{-K_{\text {tast }} t}\right)+Q_{\text {slow }}^{2}\left(1-e^{-K_{\text {slour }} t}\right)$; and Weibull function: $Q=1-e^{\left(t-t_{d} / \tau\right)^{\beta}}$. In these models, $Q$ and $Q_{0}$ represent the amount of drug released at time $t$ and amount of drug released at infinite time, respectively, $K$ is the apparent dissolution rate constant, the symbol $t_{d}$ in the Weibull function is the lag time of drug dissolution, $\tau$ is the time when $63.2 \%$ of the active principle has been released, and $\beta$ the shape parameter of the dissolution curve. In the biexponential model, $K_{\text {fast }}$ and $K_{\text {slow }}$ represent the apparent firstorder fast and slow dissolution rate constants, respectively, and the two constants $Q_{\text {fast }}$ and $Q_{\text {slow }}$ are the corresponding quantities of active principle capable of dissolving fast and slow, respectively. The above models are commonly used in dissolution characterization of oral dosage forms, and the biexponential model is not as common, but is a priori a good model due to the characteristics of the dosage form. The fits were performed using the nonlinear regression method with the S-PLUS statistical package. ${ }^{26)}$ Graphical representation, residual mean square, standard deviations of model parameters, and coefficients of determination were used as criteria to evaluate the fit of the different models considered.

In the model-independent approach to analyze and compare drug release profiles, the following parameters were applied: percentage of metoclopramide released at $8 \mathrm{~h}$; area under the curve $(A U C)$; and mean dissolution time (MDT). The $A U C$ was calculated using the trapezoidal rule. The $M D T$ was defined as the sum of different periods of time during which fractions of dose remain in the polymer matrix before release divided by the total dose. According to Lindner and Lippold, ${ }^{27)}$ the $M D T$ can be calculated by the equation: $M D T=\sum_{i=1}^{n} t_{i} Q_{i} / Q_{o}$, where $Q_{i}$ is the fraction of the doses released in time $\bar{t}_{i}=\left(t_{i}+t_{i-1}\right) / 2$ and $Q_{o}$ is the amount released overall.

Analysis of variance was performed for percentage of metoclpramide released at $8 \mathrm{~h}, A U C$, and $M D T$. These variables were assumed to have two sources of variation: rate of flow at 4,8 and $16 \mathrm{ml} / \mathrm{min}$; and the $\mathrm{pH}$ of dissolution media with sudden change and progressive gradient. Three statistical hypotheses were considered: 1) $\mathrm{H}_{1}$, there is no difference between the means of the values of rates of flow; 2) $\mathrm{H}_{2}$, there is no difference between the means of the two $\mathrm{pH}$ values; and 3) $\mathrm{H}_{3}$, the effects due to both flow and $\mathrm{pH}$ are additive.

\section{Results and Discussion}

The mean experimental value of friability was $0.19 \%$. True densities of polyamide 12 and metoclopramide dyhydrochloride were 1.02 and $1.42 \mathrm{~g} / \mathrm{cm}$, respectively. The tablet porosity calculated by (He)-pycnometry was $30.7 \%$. Toxicological, physicochemical, and pharmacotechnical properties of polyamide 12 indicate that it is a nontoxic inert polymer with good characteristics for the production of tablets by the direct compression method.

The experimental dissolution profiles $(n=18)$ of metoclopramide released from Orgasol tablets for each assay performed are presented in Fig. 2, in which considerable deviation among the tablets can be seen. The overall deviation was due to random intraindividual tablet variation and to interindividual variation which is affected by the different experimental conditions of flow rate and $\mathrm{pH}$ of the dissolution medium. The effects of flow rate and $\mathrm{pH}$ values on release kinetics are shown in Fig. 3. Each curve represents the mean $(n=3)$ cumulative amount of metoclopramide released over the sampling interval, corresponding to six different experimental conditions. $\mathrm{P} 4, \mathrm{P} 8$, and $\mathrm{P} 16$ represent the mean cumulative amount released under progressive gradient of $\mathrm{pH}$ and flow rates 4,8 , and $16 \mathrm{ml} / \mathrm{min}$, respectively. $\mathrm{S} 4, \mathrm{~S} 8$, and S16 represent the mean cumulative amount released under sudden change in $\mathrm{pH}$ and flow rates of 4,8 , and $16 \mathrm{ml} / \mathrm{min}$, respectively. Figure 3 shows that the release pattern was dependent on the experimental conditions, mainly flow rate.

Using nonlinear regression techniques, when the zero- 


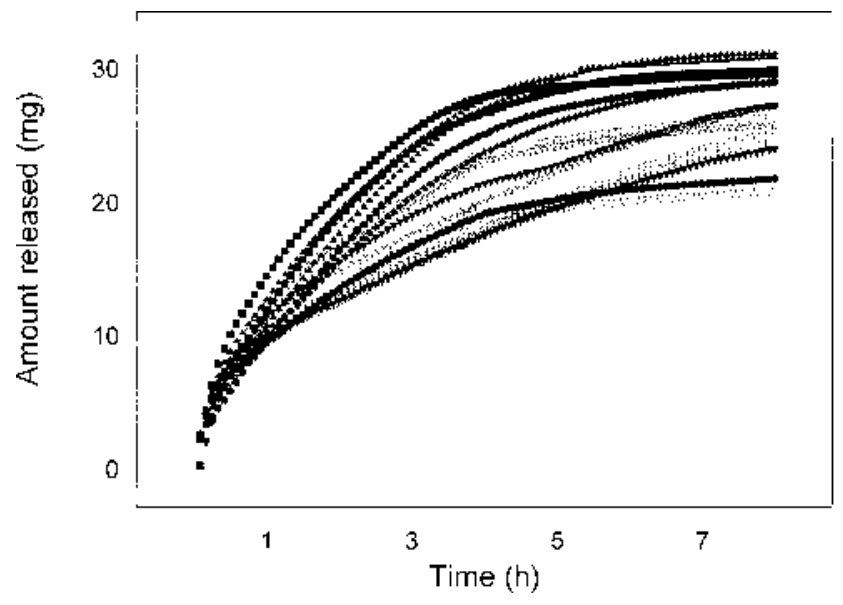

Fig. 2. Cumulative Amount of Metoclopramide Released (mg) from 18 Polyamide 12 Tablets

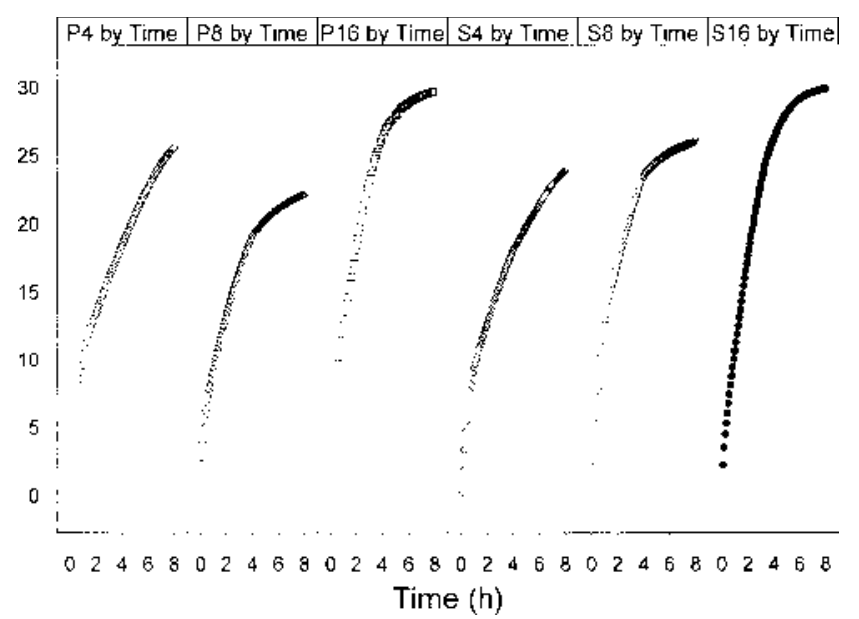

Fig. 3. Effect of Flow Rate and pH Pattern on Release Kinetics from Polyamide 12 Tablets

$\mathrm{P} 4, \mathrm{P} 8$, and $\mathrm{P} 16$ represent the mean cumulative amount released $(\mathrm{mg})$ under progressive gradient of $\mathrm{pH}$ and flow rates 4,8 , and $16 \mathrm{ml} / \mathrm{min}$, respectively. S4, S8, and S16 represent the mean cumulative amount released $(\mathrm{mg})$ under sudden change in $\mathrm{pH}$ and flow rates 4,8 , and $16 \mathrm{ml} / \mathrm{min}$, respectively.

order model was applied the coefficients of determination $\left(r^{2}\right)$ for the tests performed were low, ranging from 0.827 to 0.921 . Thus taking these results into account in conjunction with the graphic profile shape represented in Figs. 2 and 3, it can be concluded that metoclopramide release does not fit zero-order kinetics. The results of the fit to the Hixson-Crowell model showed that the coefficients of determination $\left(r^{2}\right)$ for the tests performed ranged from 0.910 to 0.997 . In spite of this apparent good fit in some cases, the residuals corresponding to the best fit (higher value of $r^{2}$ ) ranged from -2.4 to 4.2 and showed a lack of fit higher than the biexponential model (for the same experimental data, residuals ranged from -0.4 to 0.25 ). These results were predictable from a theoretical point of view, since Hixson and Crowell developed their cube root law assuming the changing surface area of multiparticulated systems, and polyamide 12 matrix tablets are nonerodible tablets that maintain a constant volume.

According to Higuchi's model, an inert matrix should provide a sustained release over a reasonable period of time and yield a reproducible straight line when the amount of drug

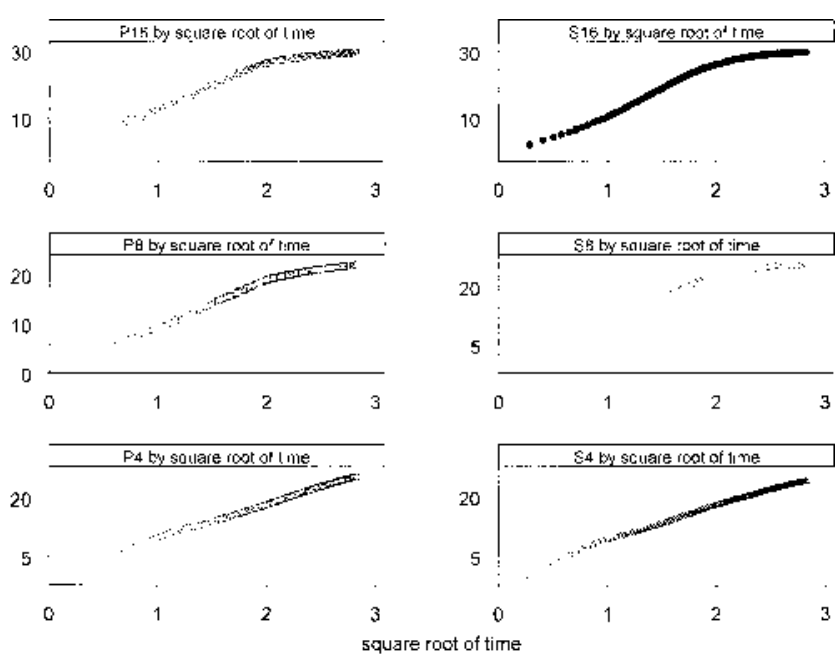

Fig. 4. Higuchi Model Representation: Mean Cumulative Amount of Metoclopramide (mg) versus the Root of Time $\left(\mathrm{h}^{1 / 2}\right)$

release is plotted versus the square root of time. The results were plotted and are shown in Fig. 4. It should be emphasized that all plots of the amount released versus square root of time have a definitive curvature. The equation would be essentially valid for systems in which the total amount present in the matrix per unit volume is greater than the solubility of the drug in the matrix substance, but when the drug loading is not greatly in excess of drug solubility, a complex situation arises. All this indicates that another approach with more physical reality than a single model would be more appropriate.

The semiempirical equation proposed by Peppas ${ }^{25)}$ called the power law of time model predicts that the fractional release of drug is exponentially related to release time. According to that author, $k$ is a constant incorporating characteristics of the macromolecular network system and the drug, and $n$ is the diffusional exponent that determines the release mechanism. The value of $n$ ranges from 0.5 , referred to as fickian diffusion, to 1 , representing case II transport, which is purely relaxation controlled. Values between 0.5 and 1 indicate anomalous behavior, or non-fickian kinetics corresponding to coupled diffusion polymer relaxation. In our data, the value of $r^{2}$ was smaller than the coefficient calculated by means of the previous models and the fitted parameter, $n$, for each tablet had a value of less than 0.5 , and therefore it was not possible to explain the kinetic release of metoclopramide by means of the power law of time model.

Experimental data were also fitted to the Weibull function, commonly used in this type of study. In spite of the flexibility of this function, the fit is not superior to that obtained with the biexponential model. In addition, Weibull function parameters do not have physical meaning.

The various models described above were applied to evaluate their suitability in describing metoclopramide released from inert matrix tablets, and several relationships were found to hold for the data in the present study. However, from a statistical point of view, the best fit was obtained when experimental data were fitted to the model $Q=Q_{\text {fast }}^{1}\left(1-e^{-K_{\text {fast }} t}\right)+Q_{\text {slow }}^{2}\left(1-e^{-K_{\text {slow }} t}\right)$. Parameters in the models were estimated by minimizing the sum of squared residuals. 

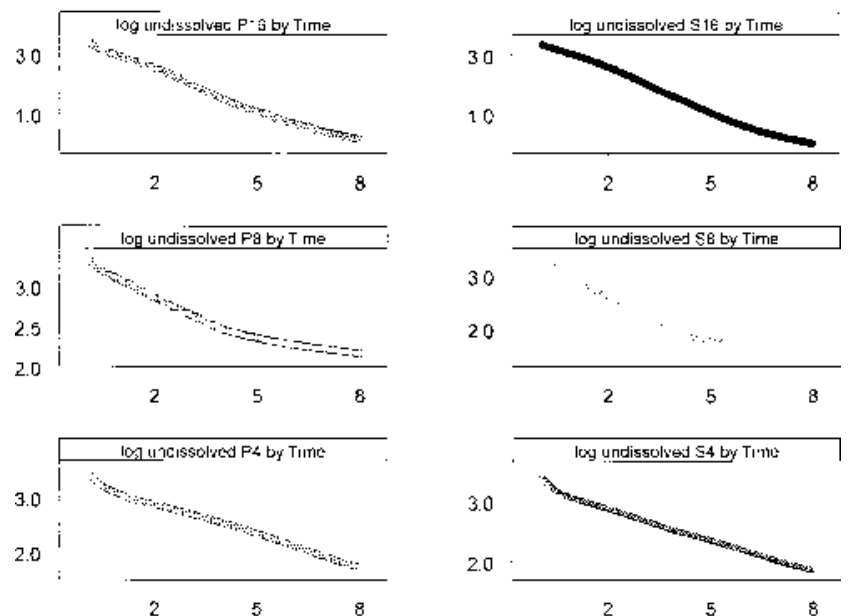

30

20

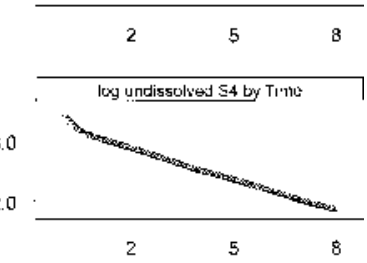

Time

Fig. 5. Logarithm of Cumulative Amount of Metoclopramide Undissolved $(\mathrm{mg})$ as a Function of Time (h)
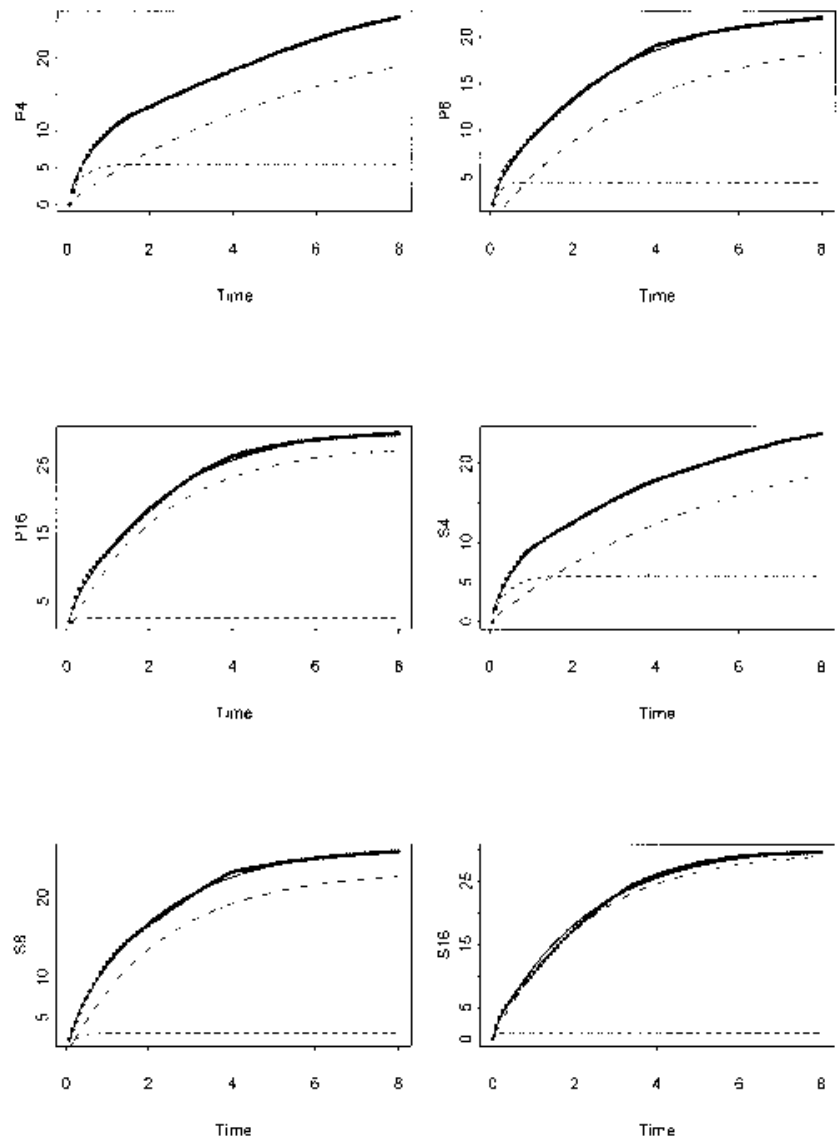

Fig. 6. Mean Amount of Cumulative Metoclopramide Released (mg) from Polyamide 12 as a Function of Time (h) for the Specimens S4, S8, S16, P4, P8, and P16 with the Two Releasing Processes

Plotting the log of cumulative amount undissolved as a function of time, $\left.{ }^{28}\right)$ it can be seen in Fig. 5 that the release of metoclopramide from Orgasol matrix tablets could be defined by a biphasic function, and in all cases it appears that there are two releasing fractions, each releasing the drug exponentially, with one fraction releasing more rapidly than the other. Figure 6 shows the experimental profiles of metoclopramide released from polyamide 12 inert tablets and the re-
Table 1. Results of the Fit to the Biexponential Model

\begin{tabular}{|c|c|c|c|c|c|c|}
\hline \multirow{2}{*}{$\begin{array}{l}\text { Flow rate } \\
(\mathrm{ml} / \mathrm{min})\end{array}$} & \multicolumn{6}{|c|}{ Sudden change in $\mathrm{pH}$} \\
\hline & $Q_{\text {slow }}^{1}$ & $K_{\text {slow }}$ & $Q_{\text {fast }}^{2}$ & $K_{\text {fast }}$ & $S C R$ & $r^{2}$ \\
\hline 4 & 25.00 & 0.17 & 5.81 & 2.37 & 4.08 & 0.998 \\
\hline 8 & 23.42 & 0.43 & 3.29 & 4.67 & 5.33 & 0.998 \\
\hline \multirow[t]{2}{*}{16} & 30.00 & 0.43 & 1.00 & 10.00 & 26.28 & 0.996 \\
\hline & \multicolumn{6}{|c|}{ Progressive gradient of $\mathrm{pH}$} \\
\hline 4 & 26.00 & 0.16 & 5.47 & 2.84 & 10.25 & 0.997 \\
\hline 8 & 20.45 & 0.28 & 4.50 & 6.00 & 10.80 & 0.995 \\
\hline 16 & 28.00 & 0.44 & 2.60 & 10.50 & 12.87 & 0.998 \\
\hline
\end{tabular}

$S C R=$ residual sum of squares; $r^{2}=$ coefficient of determination.

sults of fitting the data to a biexponential model with initial fast release followed by much slower release. The duration of the fast-release phase depends on the experimental conditions, and the slow-release phase is prolonged over $8 \mathrm{~h}$. The dissolution parameters and correlation coefficients corresponding to the biexponential model are presented in Table 1 . According to the results shown in Fig. 6 and in Table 1, it can be concluded that the fast-release rate constant increases when the flow rate increases, and there is no influence of the $\mathrm{pH}$ of the dissolution medium. The fraction of metoclopramide released quickly decreases when the flow rate increases, although the total amount dissolved at the conclusion of the test is generally higher when the flow rate is higher.

These results are expected from a theoretical point of view. Polyamide 12 is a very hydrophobic polymer, and therefore the penetration of the solvent in the tablet is a rate-limiting factor for the release of the active principle. At the beginning of the process, the active substance at and near the surface of the tablet dissolves quickly. When the dissolution process advances, there is greater resistance to the penetration of the solvent in the inside of the matrix tablet, due to the hydrophobicity of the polymer and the decreasing length of the solvent front. Thus the release rate is not constant, but decreases continuously. The biexponential model was derived from the addition of two single-exponential first-order kinetics, one with a low rate constant and the other with a higher rate constant. In biexponential function, it was postulated that two elution processes were taking place, one short term and rapid and the other more gradual and prolonged. The drug easily accessible by water immediately dissolves and diffuses from the interface between the matrix surface and the surrounding media. An easily accessible drug would be adsorbed in the surface and into the channels formed by the spherical particles of Orgasol near the surface.

According to the diffusion layer model ${ }^{29)}$ the first process involves two steps. In the first, the solution of the solid at the interface, as in the case of metoclopramide, is very rapid because it is a very water-soluble substance and accessible to the dissolution medium, resulting in the formation of a saturated layer. In the second step, diffusion occurs from this layer at the boundary to the bulk of the surrounding media. The other gradual process would occur when the drug dissolves in the interconnecting channels; the solvent must penetrate the interior of the tablet, the active principle must dissolve, and then it must be released by diffusion through the 
Table 2. Mean Values of Independent Model Parameters

\begin{tabular}{|c|c|c|c|}
\hline \multirow{2}{*}{$\begin{array}{l}\text { Flow rate } \\
(\mathrm{ml} / \mathrm{min})\end{array}$} & \multicolumn{3}{|c|}{ Sudden change in $\mathrm{pH}$} \\
\hline & $\%$ Released & $A U C(\% \cdot \mathrm{h})$ & $M D T(\mathrm{~h})$ \\
\hline 4 & 78.82 & 125.05 & 3.84 \\
\hline 8 & 85.56 & 160.04 & 2.68 \\
\hline \multirow[t]{2}{*}{16} & 96.77 & 178.95 & 2.17 \\
\hline & \multicolumn{3}{|c|}{ Progressive gradient of $\mathrm{pH}$} \\
\hline 4 & 81.84 & 137.95 & 3.22 \\
\hline 8 & 71.49 & 132.83 & 3.68 \\
\hline 16 & 96.28 & 181.95 & 2.06 \\
\hline
\end{tabular}

Table 3. F-Ratios for the Hypotheses Tested for Model-independent Dissolution Parameters

\begin{tabular}{cccc}
\hline \hline Dissolution parameter & $\mathrm{H}_{1}$ & $\mathrm{H}_{2}$ & $\mathrm{H}_{3}$ \\
\hline$\%$ Released & $26.65^{* * *}$ & $3.24 \mathrm{NS}$ & $5.15^{*}$ \\
$A U C(\% \cdot \mathrm{h})$ & $40.01^{* * *}$ & $0.68 \mathrm{NS}$ & $5.94^{*}$ \\
$M D T(\mathrm{~h})$ & $16.07^{* * *}$ & $0.19 \mathrm{NS}$ & $5.07^{*}$ \\
\hline
\end{tabular}

NS, Not significant; $* p<0.05 ; * * * p<0.001$. Dissolution parameters and hypotheses $\left(\mathrm{H}_{1}, \mathrm{H}_{2}\right.$, and $\left.\mathrm{H}_{3}\right)$ as defined in Materials and Methods.

pores. At later times, sustained release occurs following exponential first-order kinetics with a slow rate constant. The approach proposed is based on a diffusion/dissolution model, which incorporates drug dissolution from easily accessible drug as a rate-limiting step during the early phase of the dissolution process.

The variation in the release by polyamide inert matrix was also considered using analysis of variance with parameters based on an independent model approach. ${ }^{30)}$

Table 2 shows the mean values of percentage of drug release, $A U C$, and $M D T$ for the different experimental conditions tested.

The influence of rate of flow $\left(\mathrm{H}_{1}\right)$ was statistically significant for all parameters. The highest significance was observed for the $A U C$. The influence of $\mathrm{pH}\left(\mathrm{H}_{2}\right)$ was not significant for any parameter studied. However, hypothesis $\mathrm{H}_{3}$ indicates that there were interactions between rate of flow and $\mathrm{pH}$, as shown in Table 3 . These results indicate that the main source of variation was the rate of flow, and therefore the only experimental factor influencing the parameters of the model is the rate of flow. To determine the degree of influence, a Tuckey multiple-range test was carried out. Statistical differences were found between the fastest rate of flow and the two other rates. There was a significant difference $(p<0.01)$ for the parameters $A U C$ and $M D T$ between flow rates of 4 and $16 \mathrm{ml} / \mathrm{min}$ and between flow rates 8 and $16 \mathrm{ml} / \mathrm{min}(p<0.05)$. There were no significant differences between flow rates of 4 and $8 \mathrm{ml} / \mathrm{min}$.

In conclusion, the biexponential model showed the best fit with the dissolution data obtained in all tests performed in the flow-through cell. Controlled delivery of metoclopramide from an inert tablet matrix was achieved. This offers a number of advantages over existing formulations, including ease of manufacture and of release modulation, as well as reproducibility of release profiles under well-defined hydrodynamic conditions.

\section{References}

1) Chien Y. W., "Novel Drug Delivery Systems," 2nd Edition, ed. by Chien Y. W., Marcel Dekker, Inc., New York, 1997, pp. 1-42.

2) Ritschel W. A., Drug. Dev. Ind. Pharm., 15, 1073-1103 (1989).

3) Hyon S. H., Jonsei Med. J., 41, 720-734 (2000).

4) Buri P., Bull. Chim. Pharm., 123, 453-464 (1984).

5) Salomon J. L., Doelker E., Pharm. Acta Helv., 55, 174-182 (1980).

6) Gabr K. E., Eur. J. Pharm. Biopharm., 38, 199-202 (1992).

7) Stamm A., Tritsch J. C., Drug. Dev. Ind. Pharm., 12, 2337-2353 (1986).

8) Vergnaud J. M., "Controlled Drug Release of Oral Dosage Forms," ed. by Hellis Horwood Limited, U.K. 1993.

9) Agbeyoglu I. T., Drug. Dev. Ind. Pharm., 11, 2021-2041 (1985).

10) Brossard C., Lefort D., Duchene D., Puisieux F., Cartensen J. T., J. Pharm. Sci., 72, 162-168 (1983).

11) Choulis N. H., Papadopoulus H., Pharmazies, 30, 233-239 (1975).

12) Pabón C. V., Frutos P., Lastres J. L., Frutos G., Drug. Dev. Ind. Pharm., 18, 2163-2171 (1992).

13) Pabón C. V., Frutos P., Lastres J. L., Frutos G., Drug. Dev. Ind. Pharm., 20, 2509-2518 (1994).

14) Rodríguez A., Frutos P., Frutos G., S.T.P. Pharma, 6, 574-581 (1990).

15) Frutos P., Rodríguez A., Frutos G., Martín P. J., Pharm. Acta Helv., 66, 339-341 (1991).

16) Lennon P., Espuche E., Sage D., Gauthier H., Sautereau H., Valot E., $J$. Materials Sci., 35, 49-55 (2000).

17) Bruera E. D., Maceachew T. J., Spachyuski K. A., Legalt D. F., MacDonald R. N., Babul N., Harsanyi Z., Darke A. C., Cancer, 74, 32043211 (1994)

18) Albibi R., Mc Callum R. W., Ann. Intern. Med., 98, 85-95 (1983).

19) Dredán J., Zelkó R., Antal I., Bihari E., Rácz I., Int. J. Pharmaceut., 160, 257-260 (1998).

20) “United States Pharmacopoeia, USP XXIII," NF 18, Mark Printing Company, Rockville, MD, 1995.

21) "FIT Guidelines for Dissolution Testing of Solid Oral Products. Drugs made in Germany." 40 No. 4, 1997.

22) “European Pharmacopoeia." Second Edition, 2000.

23) "FDA Guidance for Industry: Dissolution Testing of Immediate Release Solid Oral Dosage Forms," August, 1997.

24) Shah V. P., Tsong Y., Sathe P., Liu J., Pharm. Res., 15, 889-896 (1998).

25) Peppas N. A., Pharm. Acta Helv., 60, 110-111 (1985).

26) S-PLUS 2000. MathSoft. Data Analysis Products Division, Seattle, WA.

27) Lindner W. D., Lippold B. C., Pharm. Res., 12, 1781-1785 (1995).

28) Leeson L. J., Adair D., Clavenger J., Chiang N., J. Pharmacokinet Biopharm., 13, 493-514 (1985).

29) Abdou H. M., "Dissolution, Bioavailability \& Bioequivalence," ed. by Gennaro A., Migdalof B., Hassert G. L., Medwick T., Mack Publishing Company, Easton, PA, 1985, pp. 11-34.

30) Kim H., Fassihi R., J. Pharm. Sci., 86, 323-328 (1997). 